Original Research Paper

\title{
Designing of Polylingual Personality Formation in a Modern Comprehensive School
}

\author{
${ }^{1}$ Bagdat Toibekova, ${ }^{1}$ Zhamilya Torybaeva, ${ }^{1}$ Gulzhan Abdullina, \\ ${ }^{2}$ Zhanar Abilkhairova, ${ }^{3}$ Ainur Zhorabekova and ${ }^{4}$ Valentina Morozova \\ ${ }^{1}$ Department of Pedagogical Sciences, H.A. Yassawi International Kazakh-Turkish University, \\ B. Sattarkhanov Street, 161200, Turkistan city, Kazakhstan Republic \\ ${ }^{2}$ Department of Pedagogy and Methods of Teaching, Korkyt Ata Kyzylorda State University, \\ Aiteke Bi street, 120014, Kyzylorda City, Kazakhstan Republic \\ ${ }^{3}$ Department of Foreign Languages, S. Seifullin Kazakh Agrotechnical University, \\ Zhenis Avenue, 010011, Astana City, Kazakhstan Republic \\ ${ }^{4}$ Department of Foreign Languages for Humanitarian Specialties, M. Auezov South Kazakhstan State University, \\ Tauke-Khan Avenue, 160012, Shymkent City, Kazakhstan Republic
}

\author{
Article history \\ Received: 02-04-2016 \\ Revised: 11-08-2016 \\ Accepted: 02-11-2016 \\ Corresponding Author: \\ Ainur Zhorabekova \\ Department of Foreign \\ Languages, S.Seifullin Kazakh \\ Agrotechnical University, \\ Zhenis Avenue, 010011, \\ Astana City, Kazakhstan \\ Republic \\ Email: ainur-zhorabekova@mail.ru
}

\section{Introduction}

Innovative processes in education imply changes in the content and technology of training and education: The optimization of the traditional educational process, the implementation by training and education subjects of search teaching and learning activities. These processes are closely related to general education system in today's schools. In conditions of a multicultural

\begin{abstract}
Today new content, new approaches, new right, other relations are offered. The content of education is enriched by new procedural skills, capacity of operating information and creative solution to the problems of science and practice with an emphasis on individualization of educational programs. In conditions of a multicultural and multiethnic environment before national school there is an important task-teaching schoolchildren along with their native language (Kazakh), Russian as a language of international communication and English as a means of initiation to the world culture. This research is conducted in order to determine effective formation of comprehensive school children's polylingual personality and educational potential of school discipline "Foreign Language" in the problem context. The implementation of objectives of schoolchildren's polylingual personality formation is determined by the system of pedagogically appropriate interactive forms, methods and techniques of teaching and educational work based on modern young pupils' mentality, the specifics of socio-cultural situation of the Kazakh state and international community. The experimental work aims at checking the working hypothesis of the study and achieving high levels of pupils' polylingual personality formation. Authors conclude the efficiency of polylingual personality formation is due to complex of organizational and pedagogical conditions combining: The creation and implementation of software, training and methodological support with account of communicative lingual-cultural orientation, as well as enriching communicative and cultural potential of the educational process subjects.
\end{abstract}

Keywords: Polylingual Personality, System, Formation, School and multiethnic environment before national school there is an important task-teaching schoolchildren along with their native language (Kazakh), Russian as a language of international communication and English as a means of initiation to the spiritual riches of the world culture (Zhetpisbayeva, 2008).

Considering that the Republic of Kazakhstan is a multinational state in which bilingualism is the norm today for everyone. Hence, polylingual personality 
formation ideally (speaking native, Russian and English languages) depends on the effectiveness of foreign language teaching in the school, where there is laid a foundation of speech abilities, skills, productive multilingualism and further process of language development. Despite the constant improvement of foreign language teaching in comprehensive schools out of the teacher's view there is a social and cultural aspect of the formation and development of the child's polylingual communicative abilities (Bokayev et al., 2012; Davletbaeva, 2008; Hrustaleva, 2002).

As complex study on the conceptual framework of multilingualism formation in a comprehensive school in modern psycho-pedagogical science is not available. The formation process of the polylingual schoolchild's personality carried out spontaneously, in fact. Therefore, now the relevance of study associated with the need for psycho-pedagogical bases of formation of pupil's polylingual personality in a comprehensive school with the communicative and lingual-cultural aspects of the content and technologies of foreign language teaching.

The aim of the study is to analyze the problem state, to define the concept "polylingual personality", the laws and principles, to check the working hypothesis of the study, to diagnose the level of pupils' polylingual personality formation.

\section{The Problem State Analysis}

The study of modern school education concepts, programs, textbooks, teaching kits in a foreign language for pupils led to the conclusion that focusing on pupils' personality development the essence of concepts and programs is differently interpreted and, therefore, the priorities are differently defined, in particular, the insufficient attention is paid to the formation of pupils' communicative and lingual-cultural competence.

On the scientific and methodological level the relevance of the problem is related to necessary development of a system for forming schoolchildren's polylingual personality, which involves the definition of principles, organizational and pedagogical conditions, training and methodological support of foreign language teaching.

The above led to undertake a special study, which aims to theoretical and methodological base and development of the formation system of pupil's polylingual personality in a modern comprehensive school and also experimental approbation and implementation in school practice.

Theoretical and methodological basis of the study constitute the conceptual fundamentals on the interrelationship and conditionality of all the elements of human culture; on the personality as the subject of activity and its social and creative entity; on the lingual- cultural conditionality of polylingual personality formation in the process of learning a foreign language as a socio-cultural phenomenon.

\section{Definition of Personality}

In order to determine the conceptual fundamentals of our study, we applied to the interpretation of the definition of personality in philosophy, psychology and pedagogy.

"Personality is common and scientific term referring to: (1) The human individual as the subject of relationship and conscious activities (person, in the widest sense), or (2) a stable system of socially significant features characterizing the individual as a member of a society and a community" (Ilichev and Fedoseev, 2010).

Psychologists, studying personality in the true sense, usually analyze the core of the personality as a subject of his own activity, highlighting in the structure the ability, temperament, character, strong-willed qualities, emotions, motivation and attitudes. However, large theoretical difficulties, associated with the problem of personality structure, are beyond all personality theories and psychology in general.

"Personality (in psychology) is a system quality, acquired by the individual in the subject activity and communication characterizing him from involvement in social relations" (Petrovsky and Yaroshevsky, 1985).

In social psychology, personality structure is derived from the structure of interaction of the individual with other people and sociality in whole to which he belongs. "Personality is an individual-socioindividual being a subject of social influence, social relations, social correlation and mental-conscious reality" (Yurchuk, 2000).

For the world representation, you can use the concept of linguistic mentality, which consists of the individual's belonging features to the socio-cultural environment and the characteristics which are determined by the sociocultural environment. Language, being a form of existence of human mental activity, covers all aspects of an individual and social life and is an integral part of human nature, practical and theoretical activity of both the individual and society.

In philosophy there were found solving ways of major linguistic problems. "We comprehend the language of its compliance with human nature, representing as a unity of body-soul-spirit" (Heidegger, 1993).

Language should be considered "as a place for a whole sole, all the spiritual way of life and creative ideas of the people" (Kitaygorodskaya, 1982). All scientists accept the axiom that language is a form of consciousness existence which raises the problem of the relation of language and reality. 


\section{Definition of Worldview}

"The worldview, displayed in the human mind, is a secondary existence of the objective world, fixed and realized in a unique manner. This material form is the language, which serves as the objectification of the individual human consciousness only as separate monads of the world" (Kolshansky, 1990).

As the main feature of the personality is consciousness and self-awareness, for our study it makes sense to consider the content of the concept of linguistic consciousness and self-awareness. In the scientific literature, the term "linguistic consciousness" is undefined. Its near-term is such as the language worldview, the strategy and tactics of speech behavior.

According to Shmelev (1989), "speaking of language consciousness, we must bear in mind the peculiarities of speech behavior of the individual, which are defined by the communicative situation, its linguistic and cultural status, social class, gender, age, mental type, outlook, biography and other constant and variable parameters of the individual. One of the ways to represent linguistic consciousness is a thesaurus."

Among scientists there is no consensus on the identification of linguistic consciousness. GV Kolshansky claims "that the language is a form of mastering the world and it is not a special form of the world. That is why we cannot speak separately about linguistic consciousness, about linguistic third world and about language worldview" (Kolshansky, 1990, p. 26).

On the contrary, linguistic relativity hypothesis in its extreme subjectivist formulation is aimed at finding of dissimilarity, discrepancy of the original "language worldview", considering that it is impossible to comprehend objective worldview through language. Hypertrophy of the subjective misinforming side of linguistic meaning gives the wrong idea about the structure and function of language.

"On the whole, the language does not impose upon us this or that perception of reality, but on the contrary, the reality is reflected in the different languages by virtue of non-identical conditions of material and social life". (Mechkovskaya, 1983)

It is important to emphasize that the definition of the language features, that have function differentiating the meaning, is determined by the culture in which these reality items are functioning. If we consider the linguistic worldview as the human factor, implemented in all language educations, it is a cognitive activity of different groups of people, due to historical, geographical, cultural and other conditions within a single objective world.

"It is correct to speak not about a language worldview. But about language thinking view, i.e., a conceptual worldview" (Kolshansky, 1990, p. 30). A second language acquisition due to the restructuring of the implicit worldview of the subject:
- Changing the connotative meaning of objects due to the new emotionally charged images

- Creating a common emotional mood attitude, common categorization circuits are built in the minds of a conceptual image of the world

- Reorganization of the categorical structure of individual consciousness, forms of ordering and classification of objects of surrounding social reality

We can agree with A.R. Luria, who writes: "Both competence in the language (language ability) and use of language (linguistic activity) do not appear immediately and they are two independent phenomena. We might think that competence in the language is the result of its application and only in result of the active reflection of reality and active communication there is a child's language comprehension". (Leontiev, 1997)

Among the general scientific methods of studying the phenomena of reality, there is a significant role to comparison. According to Ushinsky (2005) "comparison is the basis of all kind of understanding and all kind of thinking. Everything in the world we know no way than it is through the comparison".

This position is confirmed in L. Sherba's works "It is nothing to notice in the mother tongue, it is simple and self-evident in it and it is no doubt, however, the second language, studied in comparative terms, helps to reveal a variety of means of expression in the native language, too" (Mechkovskaya, 1983, p. 6].

\section{Definition of Lingual Personality}

Shmelev (1989) understands a lingual personality as "the totality of human abilities and characteristics that lead to the creation and perception of speech works (texts), which differ in the degree of structural linguistic complexity, depth and accuracy of reality reflection, a certain target areas".

The most detailed description of the lingual person is given by Yu.N. Karaulov. He identifies three levels in the structure of the lingual personality:

- Verbal - semantic is normative language acquisition;

- Cognitive, which units are concepts, ideas, making each lingual person's "worldview", reflecting the hierarchy of values

- Pragmatic, involving the objectives, motives, interests, attitudes and intentionality (Shmelev, 1989, p. 7)

At the zero verbal semantic level as the units there are the individual words and the relationship between them covers all the diversity of paradigmatic, semantic syntactic bonds together and stereotypes are standard phrases, simple sentences.

At linguistic-cognitive (thesaurus) level as the units there are generalized, major concepts, ideas, epitomized 
by the same words of the zero level, but had descriptor status. Stereotypes correspond to standard stable relationship between descriptors. Yu.N. Karaulov concludes that the proper lingual personality starts from this level, because only starting from this level, it is possible an individual choice, personal preference for one concept to another.

In our understanding the nature of the lingual person goes beyond linguistics. The speaker always expresses himself as a person and only in this case it is possible to make contact with other people. In each statement speaker appears with certain individual, ethnic, national and cultural characteristics, detecting particular worldview, speech thinking, ethical and valuable systems.

Need to speak is a result of comparing the own understanding of the act or event with the ethical ideal. This component of personal substructure has great educational and developmental potential.

The key to successful personal development of the individual is his interpersonal experience that, on the one hand, is associated with the cultural values of the brought up individual by community, on the other hand, with the objective forms of cultural development. As Leontiev (1977) pointed, "personal experience is a kind of fusion of his own personal experience, the experience of other people and the experience of society".

The experience is closely linked to the language, as the history of human separation from nature and the development of his social practice is inseparable from language. "Language is that can be generalized and transferred to experience of socio-historical practice of mankind" (Leontiev, 1977, p. 129).

Language helps intensive socialization of human activity, development of an active and practical and meaningful relationship to reality. A second language acquisition develops cognitive capabilities of human comprehension of the world, communication skills, including the emotional sphere and social attitudes in the structure of personality. If the experience of the person and the historical experience of a society is the basis of people mutual understanding, the language serves as a means to achieve it.

According to Kuzovlev (1999) in terms of schooling, "a foreign language is not a function of assigning public experience of getting direct knowledge of reality, but as a means of thought expression of objective reality".

In the process of learning a new means of communication and representation of reality phenomena formed by the pupils' awareness of themselves as a lingual person, which could have a significant influence on schoolchildren's overall culture.

Based on the above concepts "linguistic worldview" and "lingual person", we offer interpretation of the concept "polylingual person" based on objective sociopolitical changes in the conditions of intercultural and language communication in the modern world. At the present time, when learning a foreign language is actionoriented, motivated by real necessity and possibility of international communication (including through the Internet and telecommunications), which takes a massive scale, it is possible to speak about a change of some individuals' consciousness, but the current young people generation's, studying at school.

So, the concept of polylingual person we include the concept of personality, individual consciousness formed under the influence of several languages acquisition, which leads to a new understanding of the world, development of communicative and intercultural competence to harmonize interpersonal and intercultural communication.

\section{Polylingual Person Formation}

The priority of polylingual person's culture formation in pedagogical process is development and education:

- Natural personal qualities: Communicability, linguistic skills, empathy, reflexivity

- Language communication culture: Communication and speech culture, linguistic and logical thinking

- Information culture: Communicative-cognitive needs, mental health of emotional-sensual sphere

- Features of social culture: Tolerance in communication, values, active life position

Polylingual personality formation occurs in the process of acquiring the native language and culture and learning another language, initiating to the culture of the people-language learning speaker, to the mentality, norms and values of another national culture (Galskova, 2004). In the process of learning a second and third language is re-socialization of the lingual person, which is usually understood as the mastery by individual of socio-cultural knowledge, values and norms of other culture, which is not "native", but become familiar and comprehensible (Milovanova, 2007).

Hence, researchers (Milrud, 2004; Shatilov, 1986) refers to a polylingual person as a competent speaker of native and non-native languages, which should show the following competences:

- Lingual-having a system of learning language information according to the levels: Phonetics, vocabulary, morphology, word formation, syntax, base of text stylistics

- Verbal-having thought forming and formulating ways through language and able to use such methods in the process of speech perception and production

- Communicative-knowledge, abilities, skills necessary for pupils to communicate, depending on 
the scope, objectives and circumstances of communication (ability to communicate in the learning language.)

- Lingual-cultural-knowledge, abilities, skills necessary for pupils to understand the history, culture and mentality of the language learning country people, as well as tolerance to the customs, traditions and lifestyle

Taking into account that formation of schoolchild's polylingual personality is based on the main fundamentals of linguistics disclosed its laws in the structure, language semantics, its development and operation. The principles on language as a means of communication, on person's lingual and verbal abilities, on social problems of language, on similarities and differences between native and Russian languages are the basis for learning a foreign language.

System of polylingual personality formation is based on the following fundamental ideas.

The formation process of schoolchild's polylingual personality based on the latest scientific and theoretical advances of methodological, psycho-pedagogical and methodical level, student-centered pedagogy, activity developing system of training, synergistic approach as the basis of the socialization of the lingual person.

\section{Approaches of Polylingual Personality Formation}

The bases of our system are laws, which essence is in a positive formation of schoolchild's polylingual personality in learning a foreign language lead to the following factors:

- Student-centered learning a foreign language, considered as pupil's self-creation process based on internal activity and development of personality in creative activity

- Activity organization of teenagers' training actions at all stages of lesson (motivation, statement and solving by students of educational problems, diagnosis, correction, selecting one of the homework tasks) that promotes the creative development of polylingual personality

\section{Laws of Polylingual Personality Formation}

In addition to the general laws of learning inherent in any educational process, there are private laws and principles that relate to specific aspects of education and to every school discipline, in particular, to learning a foreign language. Based on theoretical fundamentals of modern linguistics: The distinction of language and speech, language and speech systemic principle, approach to language as a sign system and verbal activity, interest in the sense of the language, we define the following laws that promote positivity in the formation of schoolchild-teenager's polylingual personality in learning a foreign language:

- Based on mother tongue: Knowledge of the positive and negative influence of the mother tongue on Russian and foreign languages acquisition (knowledge of similarities and differences between them)

- Language training, in accordance with the concept "language" as a sign system, a sound model of objective reality as speech and verbal ability, as a set of tools in the process of intercultural communication. Words that represent language units, are acquired by a person as meaningful only if vocabulary and grammar meaning is received by his thought, as well as extra linguistic phenomena that are consistent with the language units

- $\quad$ Speech and communication skills of bi- and multilinguist are acquired by the ability to feel the expressive and cultural connotations of lexical, phraseological and text units. Language learners perceive the reality, the inner world of the personality, the national identity

- Polylingual person is the personality, mastered the language, linguistic, communicative and lingualcultural competencies-it is formed by skillful organization of speech activity by creating thematic educational and verbal situations, close to nature

\section{Levels of Language}

The process of learning a foreign language is based on the real-life language in the internal relationship of all its levels: Phonetic, lexical, word-formation and grammatical (morphological and syntactic). The unity of all units and levels of language is manifested primarily in its communicative function, which acts as the main feature of the language, its essence (Leontiev, 1976).

We note that in the process of learning a foreign language it is necessary to take into account first of all functional and communicative aspects, carried out under the scheme: Communicative intention (need)-thought (the subject of communication)-a means of communication (grammar and vocabulary). This scheme is in its basic outline reproduces the order of speech production, it helps learners using certain means to express their thoughts, feelings and experiences; as well as the functional aspects, involving the study of language units in terms of their functioning in a speech that reveals the interaction of semantics and linguistic knowledge of the world, i.e., the adequacy of its reflection in the human mind in the form of ideas, concepts, opinions, theories. 
Since polylingual personality formation, capable of being an active participant in intercultural communication, is a strategic objective of foreign language teaching. This requires the creation of pupils' respective language worldview through acquiring lingual-cultural units-concepts and their names-words with the national-cultural halo (non-equivalent, background and connotative lexicon), phraseological units, communication clichés (greetings, congratulations, acquaintance, etc.) and cultural texts.

In psychology, multilingualism is understood as a manifestation of the interaction and functioning mechanisms of speech in different languages (Kitaygorodskaya, 1982). The highlights of the study are particularly pupils' mental processes during thoughts transmission using the codes of three languages (Kharisov, 1998).

For verbal communication in a foreign language there must be some reasons, needs, i.e., motivation, which is the starting mechanism of speech activity in that language. This is an action of content-logical plan: Definition of the subject statements, establishment and regulation of its logical sequence in the native language. The next step of displaying general mechanism of verbal activity is an interior design of statements and internalization of inner speech (Karaulov, 1989).

\section{Scientific Approach}

The scientific approach to the question of the speech mechanism is ambiguous (Zimnaya, 1989). For all the merits of scientists' researches in their works there no sequence of language operations in general and in different types of speech. More complete models of the mechanism of speech production are presented in Kubryakova's works (1986), in which there are highlighted motivational and incentive, thought forming, verbal and non-verbal and verbal stage itself.

The essence of the teacher's organizational work is to create a structure of the lesson, helping to achieve this goal, the components of which are means of goal achievement, place, time, technology of solving specific learning objectives, facilitating the implementation of the ideas to achieve the pupil's zone of proximal development (Vygotsky, 1996).

Serious learning activities of pupils is considered as the cognitive activity caused by motivation, consequence of which is formulation of a learning task by the pupils themselves, organization of pupils' creative activity, diagnosis, self-correction and obtaining high efficiency. This approach to the lesson construction is called as Activity Approach (Leontieva, 2000).

\section{Key Aspects of Polylingual Personality Formation}

In this study, we substantiate the key aspects of polylingual personality formation which is to achieve:

- Effectiveness of the problem implementation of polylingual personality formation constructing it as a methodical system, which represents the possibility of acquiring language, speech and communication skills by pupils in the complex

- Efficiency of polylingual personality formation: Formation of the pupils' language and linguistic, communicative and lingual-cultural competences

- Polylingual personality formation with skillful creation at the lessons of foreign language the thematic verbal situations, close to nature, contributing to acquisition of communication skills in the dialogue of cultures

These key aspects define general didactic (scientific character, availability, system character, consistency, principle of consciousness, activity, visualization, collective character of learning and pupils' individualization), linguistic (functional and semantic) and methodological principles (practical orientation, account of native language, communicative, functional, cognitive and lingual-cultural) of learning a foreign language.

\section{The Principle of Developing Education}

In the study, we rely on the principle of developing education, promoting development of the child's personality in general and polylingual personality, in particular and on the functional-semantic principle involving the language acquisition at a level of language sense. The implementation of this principle in language learning is, firstly, that each unit of speech and language, any linguistic category is learned by pupils in verbal communication; second, the process of language learning is for pupil an activity, content and structure of which are verbal and language components.

\section{Communicative Principle}

Communicative principle as a guiding principle of foreign language teaching in comprehensive school puts forward as the main, overriding problem of introducing pupils with the practical skills of English speech, verbal communication skills and verbal activity in a foreign language (Passov, 1991).

As the analysis of the research, communicative language lessons focus includes: (1) Creation of conditions that stimulate pupils' desire to the verbal activity in English; (2) a comprehensive acquisition by pupils of different levels of language elements, as in any particular utterance, pupils will inevitably have 
to deal with lexical-semantic and phoneticphonological and syntactic facts; (3) complete mastery of abilities and skills of listening, speaking, reading and writing.

The content, organization and conduction of foreign language classes define the force of impact on the pupils' educational process.

\section{Opportunities for a Foreign Language Learning}

To improve the effectiveness of foreign language lessons in modern conditions there are many opportunities.

The first of them can be teaching pupils to learning methods, teaching methods for a foreign language learning, which are necessary for pupils' efficient independent work to master them.

Acquiring any discipline in general and a foreign language to a greater extent is possible only with the active performance of each pupil, their involvement in the verbal activity.

The lack of pupils' natural needs and necessity to use the language in communicative purposes creates great difficulties for both teachers and for them (Elchieva, 2004). The need may arise only if such an organization of pupils' educational activity, which can cause high motivation, providing not only their activity in the classroom, but also maintaining its strength in extracurricular hours. Interest in the discipline, desire to acquire it depends largely on what kind of education technology is used as the teacher teaches and how pupils learn (Nyshanova, 2008).

Careful preparation for foreign language lessons is another opportunity to increase its effectiveness.

Language acquisition is carried out primarily in the classroom. Modern foreign language lesson is a complex formation. Preparing and conducting it demand from teachers more creative forces spending.

First, various problems are solved at the lesson. At every lesson, pupils should certainly get a "supplement" to the practical knowledge of the learning language. It may be expressed in a better listening comprehension by learning new words, new forms of grammatical structures; in acquiring knowledge of the country language culture in the field of literature, music, history, that is, pupils are immersed in the national culture and national psychology of the learning country language.

In pupils' opinion the teacher is primarily a speaker of teaching them a foreign language. Pupil perceives a foreign language teacher as a linguistically educated person, familiar with foreign language culture, an interesting interlocutor in their native language. The teacher "represents" the pupils the culture of the country study peoples, introduces them to the traditions and cultural monuments, outstanding people, writers, artists. He inspires pupils to learn a foreign language, organizes the process of acquiring it, creates an atmosphere of a foreign language, the conditions for acquiring it, providing a tangible promotion of pupils ahead (Zaikina, 2007).

Therefore, in preparing for the next lesson, it is important for teacher to have in mind the didactic properties and functions of the selected means of teaching, clearly imagining solutions to any methodological problems that or other teaching tool can be most effective.

It is also necessary to note that to solve a number of didactic tasks in the classroom more effectively it can be methodically correct using information resources on the Internet, through which it is possible to improve listening skills through authentic audio texts on the Internet; to increase vocabulary, both active and passive vocabulary of modern language; to form a stable motivation of foreign language activities.

In addition, the process of polylingual personality formation is more effective if it carried out on the material of art works created in different cultures. Since the educational potential of poetry, folklore, music, literature, cinema, practice of their translation and a special discussion is sufficiently large, so it allows students to form personality-significant relation to moral and aesthetic phenomena, providing personal apprehension generated by society values, ideas, principles, ideals.

In general, the implementation of the program of polylingual personality formation in the school should be regarded as one of the areas of student-centered learning, which provides the intellectual, spiritual and moral, aesthetic improvement of the students, creates a need, ability, willingness and preparedness to self-focused work of self-education, self-upbringing.

\section{Findings and Conclusion}

The aim of our experimental work was to check the working hypothesis of the study. For the validity and evidence of it, in the course of controlling and forming experiments there should be identified: (a) Some differences in the level of competence formation of pupils' polylingual personality in the experimental and control groups; (b) in the experimental groups in forming polylingual person significant changes should be observed.

To diagnose the level of competence formation of pupils' polylingual personality there are used certain techniques: Situational-mediated communication in order to identify the level of formation of the communicative competence, relations in intercultural communication for the detection of formation of lingualcultural competence, interrelated learning some kinds of verbal activity and others. 
Our approach focuses on the development of effective social dialogue-oriented and practical orientation in learning a second language. We believe that among the factors reducing the success of teaching foreign language communication we should highlight the problem of parity violation of communicants in the relations with other cultures. The conclusion about the actualizing possibilities of foreign language in the selfrealization was the basis of the author's program for the competences development of pupils' polylingual personality. The key to understand school teachers, parents, students and other components of upbringing and educational polylingual environment is reflected in developed by us, "Methods of polylingual personality formation" which was verified in the pedagogical work at school 8 in Shymkent city in South Kazakhstan.

Comparative analysis of the results of pedagogical cuts, performed on the initial and final stages of experience-pedagogical work allows us to conclude significant positive changes in the level of competencies formation of experimental group schoolchildren's polylingual personality.

Thus, the number of pupils with a high level of the quality formation has increased in comparison with the initial data twice - from 11.2 to $24.5 \%$, a positive dynamics is also noted in relation to a medium level (the initial data is $27.4 \%$, final is $56.1 \%$ ). The number of pupils with a low level of competencies formation of schoolchildren's polylingual personality is significantly reduced (from 53.2 to $19.4 \%$ ), a minimum level of the quality formation by the results of experiencepedagogical work in the experimental group is not marked, it is a clear indicator of the effectiveness of the developed system implementation of schoolchildren's polylingual personality formation. It should be noted that the most significant changes are characteristic for motivational-valuable and activity components of polylingual personality whose initial values in both groups were the lowest. This suggests that learning a foreign language by schoolchildren, according to the system we have developed, provides a holistic approach to solving the problem. The control classes, where learning a foreign language was carried out according to traditional methods, without focusing on the development of polylingual person's competencies, indicators of formation remained virtually unchanged, while maintaining the predominance of medium and low levels (Table 1 and Fig. 1).

Table 1. Levels of schoolchildren's polylingual personality formation

\begin{tabular}{|c|c|c|c|c|}
\hline \multirow{2}{*}{$\begin{array}{l}\text { Levels of schoolchildren's } \\
\text { polylingual personality } \\
\text { formation }\end{array}$} & \multicolumn{2}{|c|}{ Initial } & \multicolumn{2}{|l|}{ Final } \\
\hline & CG1 & EG1 & CG2 & EG3 \\
\hline High & 10,9 & 11,2 & 18,1 & 24,5 \\
\hline Sufficient & 29,7 & 27,4 & 32,5 & 56,1 \\
\hline Medium & 51,9 & 53,2 & 43,4 & 19,4 \\
\hline Low & 7,5 & 8,2 & 6 & - \\
\hline
\end{tabular}

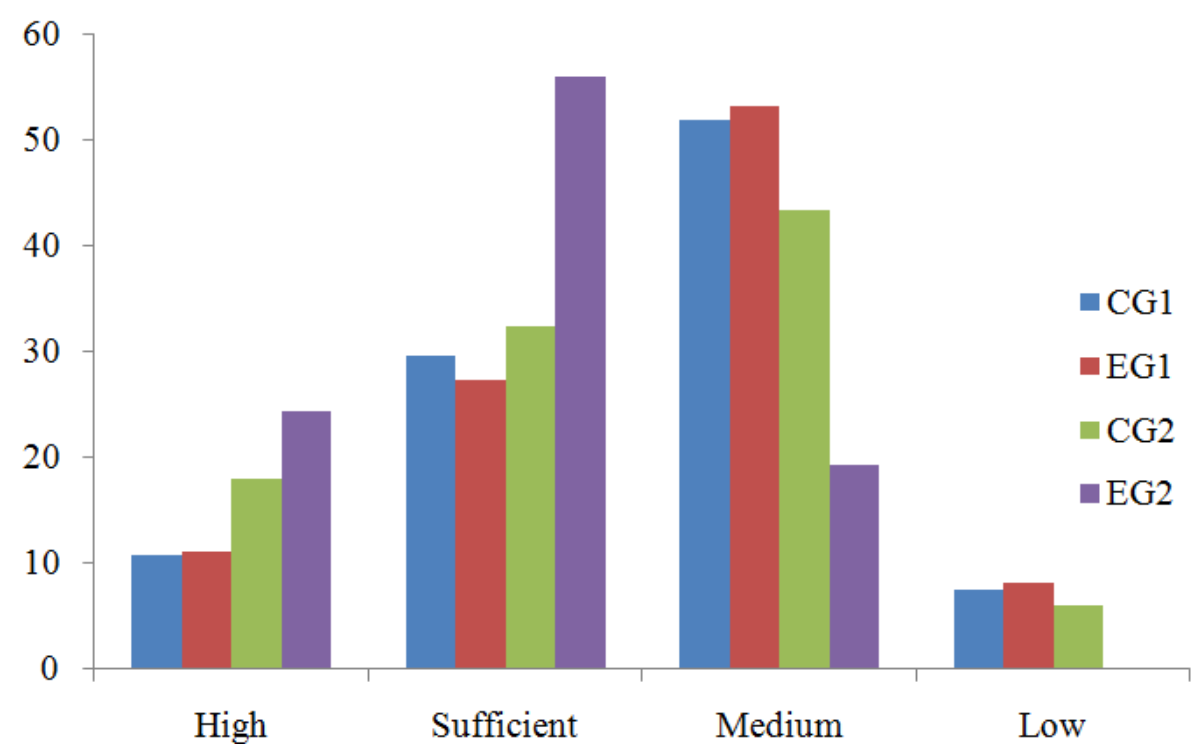

Fig. 1. Levels of schoolchildren's polylingual personality formation 
Thus, analysis of the experience-pedagogical work results, carried out in order to improve the process of polylingual personality formation in the conditions of a comprehensive school, led to the conclusion that there are problems and tasks are solved in the course of the study and the put forward hypothesis has received positive acknowledgment. Therefore, it can be argued that the use of the developed system of polylingual personality formation in the investigated aspect has a significant positive effect, which determines the optimal performance and effectiveness of pedagogical work, aimed at achieving high levels of pupils' polylingual personality formation.

So, based on our research on the formation of schoolchildren's polylingual personality we made the following conclusions:

- Model of polylingual personality formation is a holistic process of learning the native language and culture, introducing the culture in learning Russian and English in conjunction with the culture of the speaker: Mastery of phonetic, lexical and grammatical levels of native, Russian and English languages; their verbal and semantic code; linguistic and conceptual worldview

- Polylingual personality is formed in the relationship of student-centered, activity, communicative and lingual-cultural approaches

- The effectiveness of polylingual personality formation is due to complex of organizational and pedagogical conditions combining: Creation and implementation of software, teachingmethodological support with account of communicative and lingual-cultural orientation; communicative and cultural potential enrichment of the educational process subjects in the skillful use of means, forms, methods and techniques of polylingual personality formation in the course of teaching the Kazakh, Russian and English languages; integrated diagnostics of level of schoolchildren's polylingual personality formation

\section{Acknowledgement}

Authors are grateful to H.A. Yassawi International Kazakh-Turkish University, M. Auezov South Kazakhstan State University and Korkyt Ata Kyzylorda State University for the support to carry out this work.

\section{Funding Information}

This research has been funded by the H.A. Yassawi International Kazakh-Turkish University, Korkyt Ata Kyzylorda State University, S. Seifullin Kazakh Agrotechnical University and M. Auezov South Kazakhstan State University.

\section{Author's Contributions}

Zhamilya Torybaeva: Prepared the overall document, developed the methodology used in this study, designed the research plan.

Bagdat Toibekova: Participated in all experiments, coordinated the data-analysis and contributed to the writing of the manuscript.

Gulzhan Abdullina: Organized the study and coordinated the mouse work.

Zhanar Abilhairova: Collected and processed secondary data and reviewed the article.

Ainur Zhorabekova: Corresponding author, who has prepared the overall document for formatting and proofreading.

Valya Morozova: Collected data and contributed to the writing of the manuscript.

\section{Ethics}

The authors would be responsible for any issues that may arise after the publication of this manuscript.

\section{References}

Bokayev, B., S. Zharkynbekova, K. Nurseitova, A. Bokayeva and A. Akzhigitova et al., 2012. Ethnolinguistic identification and adaptation of repatriates in Polycultural Kazakhstan. J. Language Identity Educ., 11: 333-343.

DOI: $10.1080 / 15348458.2012 .723579$

Davletbaeva, R.G., 2008. Formation of elementary school pupils' modern bilingual lingual personality. Ufa.

Elchieva, S.N., 2004. Educational functions of a foreign language in the future specialist's training. Sci. Educ. South Kazakhstan, 1: 29-31.

Galskova, N.D., 2004. Theory and Practice of Teaching Foreign Languages. 1st Edn., Airis, Moscow.

Heidegger, M., 1993. Time and being. Moscow.

Hrustaleva, O.N., 2002. Formation of schoolchild's lingual personality in conditions of polylingual education. Kazan.

Karaulov, Y.N., 1989. Language and persomality. Moscow.

Kharisov, F.F., 1998. Language and nation: ecology issues in conditions of multilinguism. Kazan.

Kitaygorodskaya, G.A., 1982. Methods of intensive learning a foreign language. High School, Moscow.

Kolshansky, G.V., 1990. The objective worldview in cognition and language. Nauka, Moscow.

Kubryakova, E.S., 1986. Nominative aspect of speech activity. Nauka, Moscow.

Kuzovlev, V.P., 1999. Students' professional training in pedagogical university. MPU, EGPI, Moscow. 
Shmelev, D., 1989. Language and personality. Nauka, Moscow.

Leontiev, A.A., 1976. Some psycholinguistic aspects of the initial stage of language acquisition process. Moscow.

Leontiev, A.A., 1977. Speech and Communication. In: General Psychology, Petrovsky, A.B. (Ed.), Education, Moscow.

Leontiev, A.A., 1997. Fundamentals of psycholinguistics. Smysl, Moscow.

Leontieva, M.R., 2000. About foreign languages learning in secondary schools. Moscow.

Mechkovskaya, N.B., 1983. Language and Society. In: General Linguistics, Suprun, A.E. (Ed.), Minsk.

Milovanova, L.A., 2007. Profile-based learning foreign languages. Foreign Languages School, 8: 8-13.

Milrud, R.P., 2004. Competence in learning the language. Foreign Languages School, 7: 30-36.

Yurchuk, V.V., 2000. Modern dictionary of psychology. Elaida, Minsk.

Nyshanova, S.T., 2008. Use of new pedagogical technologies in future English teachers' professional training. Turkestan.
Passov, E.I., 1991. Communicative method of teaching foreign language speaking. Moscow.

Ilichev, L.F. and P.N. Fedoseev, 2010. Philosophical encyclopedic dictionary. Soviet Encyclopedia, Moscow.

Shatilov, S.F., 1986. Methods of teaching German in high school. Education, Moscow.

Petrovsky, A.V. and M.G. Yaroshevsky, 1985. Short psychological dictionary. Political literature publication, Moscow.

Ushinsky, K.D., 2005. Selected pedagogical works. Drofa, Moscow.

Vygotsky, L.S., 1996. Pedagogical psychology. Moscow.

Zaikina, N.V., 2007. Development of interest to foreign language learning. Kazakhstan Mektebi, 3: 40-43.

Zhetpisbayeva, B.A., 2008. Multilingual education: Theory and methodology. Bilim, Almaty.

Zimnaya, I.A., 1989. Psychology of foreign language teaching. Prosveshenye, Moscow. 